\title{
Sociolinguistics Study of Aravind Adiga's White Tiger
}

\author{
Adhip Jain \\ Research Scholar \\ Linguistics Department \\ Barkatullah University \\ Bhopal, Madhya Pradesh, India. \\ adhipjain70@gmail.com
}

\begin{abstract}
This paper comprises the sociolinguistic concepts which are hidden in the Aravind Adiga's novel 'White Tiger'. And it will let us know how Aravind Adiga managed to reach his audience effortlessly. Aravind Adiga is a Man Booker Prize Winner of 2008, for his debut novel 'White Tiger'. White Tiger is the story of a common man, who manages to attain tremendous success, later starts working as an Entrepreneur. The protagonist, Balram Halwai, narrates this novel, he sends letters to Premier of China, who will soon be visiting India. Moreover, this novel comprises of sociolinguistic elements such as the names are mostly of Indian origin, prestige feature. Aravind Adiga is being chosen as a writer to be tested on sociolinguistic grounds because there is an apt amount of sociolinguistic elements (code switching, high prestige, low prestige, etc.) in his novels. Aravind Adiga reaches the reader's heart, by using appropriate language in the manner his target audience can understand. This paper also verifies the sociolinguistic impact on Aravind Adiga, in the midst of this we realise the importance of sociolinguistic theories. Society and culture play a vital role in our language acquisition, and it shapes our respective roles in society. Ultimately, this can let us know how language variation occurs and impacts the users. Language is like a river,
\end{abstract}


it changes its directions with time, place, communities, etc, and certain meanings avert or change slightly from the original meanings.

Keywords: Sociolinguistics, colloquial, dialect, prestige, register.

Sociolinguistics is the study of the effect of society on language, which involves the cultural standards, speculations, and context, on the way language is used, and society's effect on language. Sociolinguistics tests all factors of the bond between language and society. It is the soul of any communication process. Sociolinguistic studies the changes that occur in language with time, place, and community. Carol M Eastman defined sociolinguistic as "The study that is concerned with the interaction of language and setting" (1975). Sociolinguistics covers a whole lot of variation in language usage, which signifies a person's social otherwise socioeconomic class. Sociolinguistics would be a redundant concept if linguistics properly reflected the social basis of all language use (Joshua Aaron Fishman, 2017, p. 6). Sociolinguistics lets us know about the impact of the speech community on our acquisition of language and the manner in which we will use it. The sociolinguistic situation in India is marked by an extraordinary degree of linguistic diversity which parallels the ethnic and religious pluralism of the society. Many articles published in various literary and linguistic journals instigate thoughts in our mind to go deeper in the field of study and to find out new pearls of knowledge. In order to understand the concepts of socio-linguistics, many sources of information are used such as, Samane Naderi and Ali Fazilatfar's 'Newspaper Reading Comprehension Development through Vocabulary or Structure Instruction'. In this work, the authors relate the importance of newspaper reading as a remarkable tool to develop the language learning. Reading news magazines, newspapers not only develops the language learning it also enhances the practice of active reading and perceiving the meaning as well: "An extensive literature, investigating the issue of using authentic materials including newspapers for language development, demonstrates that applying such kinds of materials are 
very helpful in language learning development (Naderi \& Fazilatfar, 2020, p. 3). Every society/ community uses language in certain way. The way in which a society makes use of language is visible in the sources through which people of society learn to use the language as a source of communication. Learners of language, try to absorb it through sources, which can make the learning process easy. Moreover, it turns out to be easier if learning takes place from authentic sources. This research paper aims to verify the sociolinguistic impact on Aravind Adiga as well as the secret behind his ability to reach his readers. Aravind Adiga is an India born writer. Aravind got his early education in Mangalore later he and his family moved to Australia so he got the rest of his education in Australia. This change of place of attainment of education made him borrow words from different languages in various regions. The notable point is that people take interest in conversation when they understand it better and it becomes easy when the communication takes place in their own dialect. Adiga employs this technique only, to communicate with his readers, to deliver his messages he uses colloquial language.

"Distinction cannot always, be carried out, since there is no absolute distinction to be made between dialect boundaries and language boundaries" (Bloomfield, 1933 Pg.444). Aravind Adiga uses this fact cleverly and to reach his target audience's heart he uses colloquial words, names, phrases, etc. The language/ dialect popular in his vicinity always had an impact on him. The manner in which, he puts forward his ideas and opinions through his characters always involve sociolinguistic features. One of the major objectives of this research is to find the smoothest way of using language to transfer messages and meanings among people in an easy and efficient manner. This in turn proves the choice of Aravind Adiga upright as an author for my research purpose because he is a Man Booker Prize Winner of 2008 for his debut novel White Tiger. White Tiger is the story of a common man, who manages to attain tremendous success, later starts working as an Entrepreneur. The 
protagonist Balram Halwai narrates this novel; he sends letters to Premier of China, who will soon be visiting India.

Adiga uses an ingenious way to make/ state his point rather than exaggerating. He uses colloquial language to reach the hearts of his target audience. This is a known fact that people understand better, when communication takes place in their own dialect. A linguist realizes that while talking about dialect no one can miss the concept of sociolinguistic prestige. They tend to take more interest and start to understand better in their own dialect. Thus, Aravind made use of this fact to deliver maximum meaning. This is one of the reasons behind Adiga's tremendous success as a writer. In addition, when one goes through his novels, he realizes that Adiga uses ways to make his novels gripping, such as a sarcastic approach or jocular approach, etc. Either way, the reader finds humor as well as meaningful messages in Aravind Adiga novels. Avram Noam Chomsky believes, "The social and behavioural sciences provide ample evidence that objectivity can be pursued with little consequent gain in insight and understanding" (Chomsky, 1965, p. 20). Whenever somebody speaks, writes, and perceives ideas, opinions, or visions, he/she understands and uses a vocabulary prevalent in his time. Language is like a river it keeps on flowing, accepting the occurring changes and hence, we find words remaining the same still getting new meanings, the branch of sociolinguistics observes. I realized Aravind Adiga plays smart, in order to reach the reader's heart, he conveyed whatever he wanted to, in a genuine way, and delivers his messages through his stories. For example-

- "Halwai, my name, means, "sweet-maker." That's my caste - my destiny." (Adiga, 2008, p. 53)

- "We were like two separate cities - inside and outside the egg [of the car]...I was in some way out of the car too, even while I was driving it." (Adiga, 2008, p. 116) 
- "I don't insult any of them by calling them "family"...I'm their boss, that's all.” (Adiga, 2008, p. 259)

Aravind Adiga uses dark humor to portray things he does not like, and wants those things to be improved. He writes about people and their ways of dealing with life. His approach immediately relates the reader to the events that occur in the novel. Readers realize that Aravind Adiga does have the quality of veracity, which he covers by sarcastic or jocular way of saying things. For example, "In the old days there were one thousand castes and destinies in India. These days, there are just two castes: Men with Big Bellies and Men with Small Bellies" (Adiga, 2008, pg. 54). Aravind sails over facts and one of them is "whenever a person feels excited, angry or pride they tend to say things in the language they feel comfortable using. Thus, a reader not only enjoys reading Adiga's novels but also learns the lesson he is trying to deliver. For example - Aravind Adiga used a limited amount of characters in his novels and to make it look realistic for his target audience, he chooses the names of his characters, which belong to Indian Origin. For example in his novel 'White Tiger', he used the names: Balram Halwai, Kusum, Ashok, Dharam, Vikram Halwai, Mr. Krishna, Kishan, Ram Persad, Vijay, Ms. Uma, Dilip, Ram Bahadur, Mohammed Asif, etc. Moreover, in this way, this method of research helps us to find out how Aravind Adiga used colloquialism, and how much to reach his target audience. Though, we know whatever the names are, a writer pours his heart out in his novel through his story, the prime focus of this research is to analyze, the manner in which Aravind Adiga did it. Sociolinguistic research tells us about how language takes its shape in society as well as how it influences its users. Thus, it makes one think about Dialectology, the subfield of sociolinguistics. It is the regional variety of language distinguished by features of vocabulary, grammar, and pronunciation from other regional varieties and constituting together with them a single language. Adiga, maintains sanity in his works and for this purpose, he uses good vocabulary. Yes, colloquial 
words are present in his works, but he tries to make an optimum mixture of standard language and colloquial words to deliver his message to reach maximum readers. "Register variations were mostly quite specific in orientation; however, newer computational analytic tools have now made generalizations much easier" (Biber and Conrad, 2014, pp1-42). Consequently, reader of any place does not have any difficulty, in understanding the message, whichever he tries to impart.

Conclusion

This research work verifies the impact of society, community, place, etc on the language used by Aravind Adiga in his novel 'White Tiger'. He made use of sociolinguistic theories to reach his audience's heart. The sociolinguistic impact on Aravind Adiga, in general, has become extremely complex, as many languages and language varieties found in our country, because of historical, political, and socio-cultural factors. The change is occurring in the way of use of language, accepted by the people living in a society is the prime focus of socio-linguistic study. It takes into account dialectology. Furthermore, the language used by writers of the same period is somewhat similar but the regional effect on them makes them different. Readers find the work more interesting if they find a similar touch of language, which in turn results in an easier understanding of the events included. 


\section{Works Cited}

Adiga, Aravind (2008). The White Tiger, Free Press. p. 101

Biber, D. and Conrad, S., 2014. Variation in English: Multi-dimensional studies. Routledge

Bolton, K. and Kwok, H., 2014. Sociolinguistics Today (RLE Linguistics C: Applied Linguistics): International Perspectives. Routledge

Book review: The White Tiger by Aravind Adiga (Winner of the Man Booker Prize 2008), Stories in Moments, Retrieved 22 March 2014

Fishman, J.A., 2017, Language and ethnicity: The view from within. The handbook of sociolinguistics, pp.327-343

Holmes, J. and Hazen, K. eds., Research methods in sociolinguistics: A practical guide (Vol. 5), John Wiley \& Sons, 2014

L Bloomfield, Language, 1933

N Chomsky, Aspects of the Theory of Syntax, 1965

The White Tiger: Booker Prize Winner 2008 by Aravind Adiga, 3 November 2009

The Rooster Coop Symbol in the White Tiger - LitCharts

Naderi, S. ., \& Fazilatfar, A. . (2020). Newspaper Reading Comprehension Development through Vocabulary or Structure Instruction. International Journal Online of Humanities, 6(4), 1-18. https://doi.org/10.24113/ijohmn.v6i4.188 Accessed date 25 $\operatorname{dec} 2020$ 